\section{SAT0353 GEOGRAPHICAL DIFFERENCES IN PSORIATIC ARTHRITIS: A TRANSATLANTIC COMPARISON}

S.B. Üreyen ${ }^{1}$, D. Solmaz ${ }^{1}$, G. Kimyon ${ }^{2}$, E.K. Gunal ${ }^{3}$, A. Dogru ${ }^{4}$, O. Bayindir ${ }^{5}$,

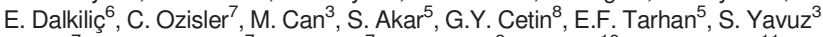
L. Kilic ${ }^{7}$, O. Kucuksahin ${ }^{7}$, A. Omma ${ }^{7}$, E. Gonullu' ${ }^{9}$, F. Yildiz ${ }^{10}$, E.D. Ersozlu ${ }^{11}$, M. A. Tufan ${ }^{7}$, M. Cinar ${ }^{7}$, A. Erden ${ }^{7}$, S. Yilmaz ${ }^{12}$, S. Pehlevan ${ }^{3}$, T. Duruoz ${ }^{3}$, U. Kalyoncu ${ }^{7}$, S.Z. Aydin ${ }^{1}$ on behalf of PsArt-ID (Psoriatic Arthritis- International Database). ${ }^{1} P s A r t-I D$, Ottawa, Canada; ${ }^{2} P s A r t-I D$, Gaziantep; ${ }^{3} P s A r t-I D$, Istanbul; ${ }^{4}$ PsArt-ID, Isparta; ${ }^{5}$ PsArt-ID, Izmir, ${ }^{6}$ PsArt-ID, Bursa; ${ }^{7}$ PsArt-ID, Ankara; ${ }^{8}$ PsArt-ID, Kahramanmaras; ${ }^{9}$ PsArt-ID, Eskisehir, ${ }^{10}$ PsArt-ID, Van; ${ }^{11}$ PsArt-ID, Adana;

${ }^{12}$ PsArt-ID, Konya, Turkey

Background: The environmental and genetic factors play a crucial role in the pathogenesis of psoriatic arthritis (PsA) which may cause a difference in disease characteristics for patients from different geographical regions.

Objectives: The aim of the study was to explore the disease characteristics, treatment choices and comorbidities in patients with PsA in different countries to see the impact of geographic factors.

Methods: PsArt-ID (Psoriatic Arthritis- International Database) is a prospective, multicentre registry in PsA, which was initially developed in Turkey in 2014, with participation of Canada since 2015 and Italy since 2017. Patients with PsA are consecutively registered to this registry with the aim of investigating the real-life data. Patient characteristics across Turkey $(n=1283)$ and Canada $(n=119)$ are compared for this analysis.

Abstract SAT0353 - Table 1. The demographics and clinical characteristics in two countries

\begin{tabular}{lccc}
\hline & TURKEY & CANADA & p value \\
\hline Female* & $827 / 1283(64.5)$ & $60 / 119(50.4)$ & $\mathbf{0 . 0 0 2}$ \\
Age (years) & $47(36-56.7)$ & $49(34-61)$ & $<\mathbf{0 . 0 0 1}$ \\
BMI $\left(\mathrm{kg} / \mathrm{m}^{2}\right)$ & $27.47(24.5-31.2)$ & $29(23.7-33.5)$ & $\mathbf{0 . 0 1 3}$ \\
At onset age for PsA & $36(29-49.7)$ & $39(30-48)$ & 0.058 \\
Smoking (package/years) & $10(3-19.7)$ & $14.5(5-26.25)$ & $\mathbf{0 . 0 0 7}$ \\
Education years & $8(5-12)$ & $15(13-16)$ & $<\mathbf{0 . 0 0 1}$ \\
SJC & $2(1-5)$ & $2(1-7)$ & 0.461 \\
TJC & $4(2-8)$ & $6.5(2-17)$ & 0.340 \\
TEP & $2(1-2)$ & $1(1-2)$ & $\mathbf{0 . 0 2 1}$ \\
BSA & $5(1-13.75)$ & $1(0-5)$ & $<\mathbf{0 . 0 0 1}$ \\
BASDAl & $37(20-54)$ & $38(22-58)$ & $\mathbf{0 . 0 2 7}$ \\
Pt GA & $45(20-60)$ & $31(12-70)$ & $<\mathbf{0 . 0 0 1}$ \\
PGA & $30(20-50)$ & $34(18-66)$ & $<\mathbf{0 . 0 0 1}$ \\
Pain VAS & $40(20-60)$ & $33(18-78)$ & $<\mathbf{0 . 0 0 1}$ \\
\hline
\end{tabular}

TJC: tender joint counts; TEP: tender entheseal points; BSA: body surface area; PtGA: patient global activity; PGA: physician global activity. All data were given $n / t o t a l ~ n$ (percentage $(\%))^{*}$ or median (first-third percentiles).

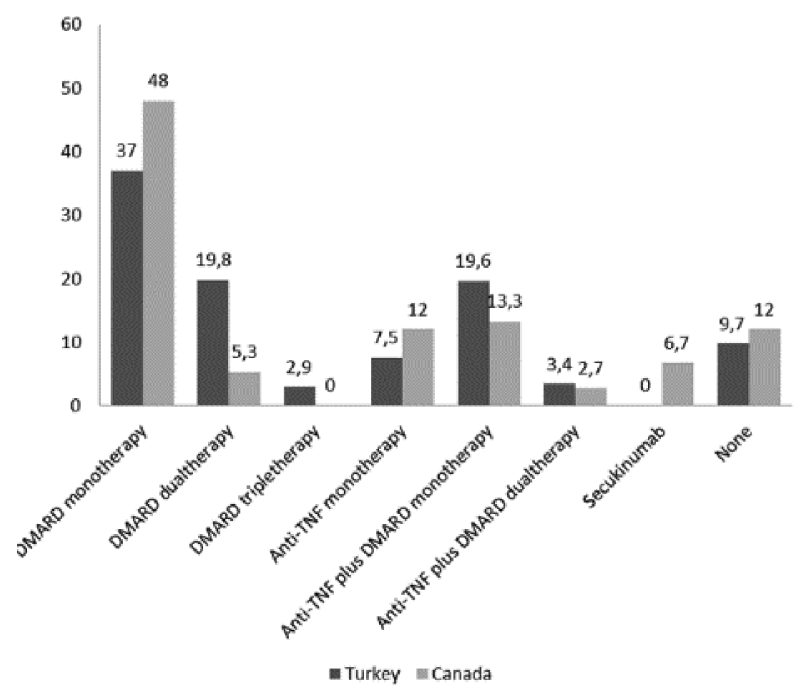

Abstract SAT0353 - Figure 1. The distribution of the treatment choices in Turkey and Canada, excluding patients with new diagnosis at the time of recruitment. DMARD: Diseasemodifying anti-rheumatic drug; anti-TNF: anti-tumour necrosis factor. All data were given $\mathrm{n}$ / total $\mathrm{n}$ (percentage $(\%)$
Results: Canadian patients were older at the time of recruitment (Table). They also were more frequently smokers, had higher duration of education and higher BMI than patients in Turkey. Patients in Canada had more frequent polyarthritis ( $66.7 \%$ vs $39.6 \%, p<0.001)$, DIP joint disease $(34.2 \%$ vs $16 \%, p<0.001)$, dactylitis ( $38.1 \%$ vs $29 \%, p=0.037$ ) nail involvement $(55.9 \%$ vs $45.7 \%, p=0.008)$ and higher number deformed joints $(29.3 \%$ vs $20.7 \%, \mathrm{p}=0.035)$ whereas Turkish patients had oligoarthritis more often ( $37.6 \%$ vs $24.8 \%, p=0.016)$. For disease activity, tender and swollen joint counts were similar for whereas the skin activity was higher in Turkish patients. There were no major differences between countries regarding treatment choices with similar frequencies of patients on biologic therapies $(34.5 \%$ vs $30.2 \%, p=0.339$ ) (figure 1 ). Although the numbers were very low, there was more frequent cancer in Canada than Turkey $(4.3 \%$ vs $1.4 \%, p=0.022)$ whereas all the other comorbidities were similar.

Conclusions: Geographical differences have impacts on the disease features in PsA, which may be due to genetic, environmental and cultural differences. The treatments are comparable suggesting a similar approach by the physicians.

Disclosure of Interest: None declared

DOI: 10.1136/annrheumdis-2018-eular.2728

\begin{tabular}{|l|l}
\hline SAT0354 & THE WORK PRODUCTIVITY AND ACTIVITY INDEX \\
SPECIFIC HEALTH PROBLEM (WPAI-SHP) AND ITS \\
ASSOCIATION WITH PSORIATIC ARTHRITIS (PSA) \\
ACTIVITY BY DISEASE ACTIVITY INDEX FOR \\
PSORIATIC ARTHRITIS (DAPSA) IN ROUTINE CARE: \\
DATA OF THE RUSSIAN PSORIATIC ARTHRITIS \\
REGISTRY (RU-PSART)
\end{tabular}

T. Korotaeva ${ }^{1}$, E. Loginova ${ }^{1}$, A. Koltakova ${ }^{1}$, E. Gubar ${ }^{1}$, Y. Korsakova ${ }^{1}$ E. Nasonov ${ }^{1}$, A. Lila ${ }^{1}$, M. Sedunova ${ }^{2}$, T. Salnikova ${ }^{3}$, I. Umnova ${ }^{4}$, I. Bondareva ${ }^{5}$, G. Zagidulina ${ }^{6}$, P. Zemtzova ${ }^{7}$ on behalf of the RU-PsART study group. ${ }^{1}$ Nasonova Research Institute of Rheumatology, Moscow; ${ }^{2}$ St. Petersburg Clinical Rheumatology Hospital No.25, St. Petersburg; ${ }^{3}$ Tula Regional Hospital, Tula ${ }^{4}$ Omsk Regional Hospital, Omsk; ${ }^{5}$ Kemerovo Regional Hospital, Kemerova; ${ }^{6}$ Kazan City Hospital No.7, Kazan; ${ }^{7}$ Nizhny Novgorod Regional Clinical Hospital $n$. a. Semashko, Nizhny Novgorod, Russian Federation

Background: Psoriatic arthritis (PsA) can lead to impaired physical function and work productivity due to chronic inflammation. The goal of PsA treatment is minimal disease activity (MDA) or Remission/Low Disease Activity (REM/LDA) attainment by DAPSA. But there is limited data about the association between PsA activity and work productivity in routine care. The Russian Psoriatic Arthritis Registry (RU-PsART) collected data from 25 rheumatology clinics in the Russian Federation regions.

Objectives: evaluate the association between attainment of REM/LDA by DAPSA and the WPAI-SHP in PsA pts in routine care.

Methods: 294 (M/F-133/161) pts with PsA, diagnosed according to CASPAR criteria, mean age $41.2 \pm 1.9$ (Min $21-$ Max 72) years (yrs.), PsA duration 6.1 \pm 5.3 (Min 0 - Max 31) yrs., psoriasis duration 13.6 \pm 10.7 (Min 0.2 - Max 54.8) yrs. were included in the RU-PsART after signing consent participation forms. Pts underwent evaluation of PsA activity by DAPSA and considered REM $\leq 4, \mathrm{LDA} \leq 14$, moderate disease activity (MDA) $\leq 28$, high disease activity $(\mathrm{HDA})>28$ at baseline. 175 out of 294 pts fulfilled WPAI-SHP. DAPSA and WPAI-SHP at the same time were available in 135 out of 175 pts. 87 out of 135 patients were able to work and operate. At the time of evaluation 82 out of 135 pts were taking sDMARDs, 19 out of 135 pts - bDMARDs \pm sDMARDs, 11 out of 135 pts - NSAID and in 23 out of 135 pts data were missing. Overall work impairment, daily activity impairment, absenteeism and presentism were calculated. $\mathrm{M} \pm \mathrm{SD}, \%$, ORs with $95 \% \mathrm{Cl}$ were performed. All $\mathrm{Cl}>1$ were considered to indicate statistical significance.

Results: Daily activity impairment was found in 91 out of 135 pts $(67 \%)$, overal work impairment - in 64 out of 87 pts (74\%), presentism - in 47 out of 87 pts (49\%), absenteeism - in 31 out of 87 pts (36\%). 40 pts out of $135(29.6 \%)$ had REM/LDA and 95 out of 135 pts (62.9\%) had MDA/HAD by DAPSA accordingly at the time of the assessment. Among pts with MDA/HAD daily activity impairment, overall work impairment, presentism and absenteeism were seen in significantly more cases compared to pts with REM/LDA - in 69 out of 95 pts (73\%) and in 22 out of 40 pts (55\%), OR 2.17 [1.0-4.69]; in 54 out of 62 pts ( $87 \%$ ) and in 10 out of 25 pts $(40 \%)$, OR 10.13 [3.40-30.16]; in 38 out of 62 pts (38\%) and in 9 out of 25 pts (36\%), OR 2.81 [1.07-7.38]; in 30 out of 62 pts $(48 \%)$ and in 1 out of 25 pts (4\%), OR 22.5 [2.86-176.80] accordingly (Fig.1). 